\title{
Personality and Friendship Satisfaction in Daily Life: Do Everyday Social Interactions Account for Individual Differences in Friendship Satisfaction?
}

\author{
Q1 ROBERT E. WILSON ${ }^{1 *}$, KELCI HARRIS ${ }^{2}$ and SIMINE VAZIRE ${ }^{1}$ \\ Q2 ${ }^{1}$ Department of Psychology, University of California, Davis, CA, USA \\ ${ }^{2}$ Department of Psychology, Washington University in St. Louis, St. Louis, MO, USA
}

\begin{abstract}
Who are the people who maintain satisfying friendships? And, what are the behaviours that might explain why those people achieve high friendship satisfaction? We examined the associations between personality (self-reports and peer-reports) and friendship satisfaction (self-reports) among 434 students. We also examined whether role personality (how people act with their friends) and quantity and quality of social interactions using ecological momentary assessment mediate the associations between personality and friendship satisfaction. Extraversion, agreeableness, conscientiousness and (low) neuroticism were associated with higher levels of friendship satisfaction. These associations could not be accounted for by individual differences in role personality. In addition, our results suggest that quantity of time spent with friends and quality of friend interactions (depth of conversation, selfdisclosure and lack of emotion suppression), although associated with friendship satisfaction, do not account for the associations between trait personality and friendship satisfaction. Future research should examine other potential interpersonal processes that explain why some people are more satisfied with their friendships than others and the consequences of friendship satisfaction (e.g. for well-being). Copyright (C) 2015 European Association of Personality Psychology
\end{abstract}

Key words: social and personal relationships; social interaction; social support

\section{INTRODUCTION}

Maintaining satisfying relationships with friends is an important part of living a full and contented life. A growing body of empirical evidence supports the intuitive notion that friendship satisfaction is an important determinant of life satisfaction and adjustment (Buote et al., 2007; Demir \& Weitekamp, 2007; Heller, Watson, \& Ilies, 2004). However, friendships are not immune to the difficulties inherent in any social relationship, and many people struggle to find and sustain satisfying friendships. This raises two related questions that will be addressed in the present paper: Who are the people who maintain satisfying friendships and what are the daily behaviours and friendship-relevant processes that explain why certain people achieve high friendship satisfaction?

Before addressing these questions, it is helpful to consider friendship satisfaction in the context of overall life satisfaction. A meta-analysis by Heller et al. (2004) determined that friendship satisfaction is best conceptualised as a facet of life satisfaction. Promoting life satisfaction is a primary goal of both individuals and policy makers. Recent initiatives (e.g. United Nations Happiness Report and Gross National Happiness Index) have investigated various facets influencing life satisfaction (e.g. job satisfaction, marital satisfaction, security and health; Helliwell, Layard, \& Sachs, 2013; Kramer,

*Correspondence to: Robert E. Wilson, Department of Psychology, University of California, Davis, CA, USA.

E-mail: wilson@ucdavis.edu
2010). Surprisingly, friendship satisfaction has received little attention despite its apparent importance as a determinant of life satisfaction (Heller et al., 2004; Ozer \& Benet-Martinez, 2006). To put this research gap in perspective, consider that a search in the popular PsycINFO database for the terms 'relationship satisfaction' and 'job satisfaction' returned 11370 and 33798 results, respectively. In contrast, the term 'friendship satisfaction' returned only 255 results. Such a gap speaks to a lack of attention paid to a core aspect of life satisfaction.

\section{Determinants of friendship satisfaction}

One contribution of the current study will be to provide empirical evidence regarding the mechanisms linking personality to friendship satisfaction. In order to understand these processes, we begin by examining the personality traits associated with friendship satisfaction. After identifying who typically has higher friendship satisfaction, we will explore the daily behaviours and friend-specific interpersonal processes that may explain why certain personality characteristics are associated with friendship satisfaction (Figure 1).

The mediation model portrayed in Figure 1 is based on the theoretical framework outlined in PERSOC (Back et al., 2011). PERSOC postulates that dispositions (e.g. agreeableness) and interpersonal outcomes (e.g. friendship satisfaction) can mutually influence each other over time. Further, the association between these broad constructs can be explained by the daily behaviours and interpersonal patterns that are specific to the context of friendship interactions. 


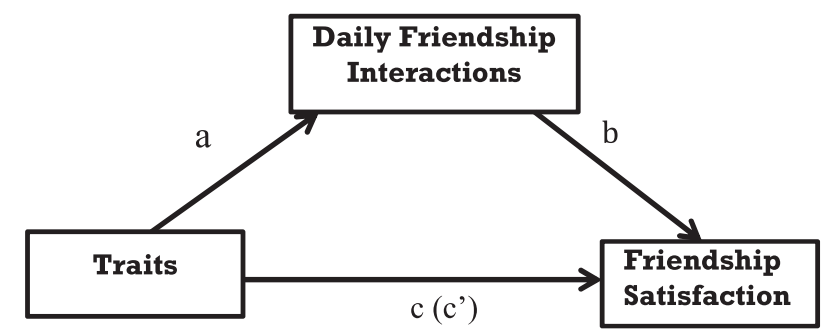

Note: Path a represents the raw correlation between Traits and Daily Friendship Interaction variables. Path $\mathrm{b}$ represents the unique variance in friendship satisfaction predicted by Daily Friendship Interaction variables, above and beyond the variance predicted by path a. Path c represents the raw correlation between Traits and Friendship Satisfaction (total effect). Path c' represents the association between Traits and Friendship Satisfaction after accounting for Daily Friendship Interaction indirect effects (direct effect).

Figure 1. Mediation model based on PERSOC (Back et al., 2011).

Because this is among the first empirical studies to examine these complex processes, we focus on one aspect of this model: how global personality and interpersonal behaviours predict friendship satisfaction. The first step is to establish which personality traits predict friendship satisfaction.

\section{Who has satisfying friendships?}

What has past research found regarding the personality characteristics of people with satisfying friendships? There are not many studies that address this question directly, but work in the domain of romantic relationships provides clues about the personality processes influencing interpersonal relationship satisfaction. For example, research has found that all of the Big Five personality traits predict romantic relationship satisfaction to some extent (Heller et al., 2004; Malouff, Thorsteinsson, Schutte, Bhullar, \& Rooke, 2010; Schaffhuser, Allemand, \& Martin, 2014). Specifically, high neuroticism, low conscientiousness and low agreeableness are consistently found to be strong predictors of marital problems and low relationship quality (Finn, Mitte, \& Neyer, 2013; Karney \& Bradbury, 1995; Karney \& Bradbury, 1997; Kelly \& Conley, 1987; Malouff et al., 2010; Roberts, Kuncel, Shiner, Caspi, \& Goldberg, 2007; Watson \& Slack, 1993). Extraversion also appears to have a moderately positive relationship with marital satisfaction, perhaps because extraverts typically have higher positive affect (Diener \& Lucas, 1999; Heller et al., 2004; Lucas \& Fujita, 2000). The relationship between openness and romantic relationship satisfaction is more nuanced, with openness predicting both positive outcomes (e.g. marginally higher marital satisfaction; Heller et al., 2004) and negative outcomes (e.g. increased likelihood of divorce; Solomon \& Jackson, 2014).

Do these same patterns hold for friendship satisfaction? Friendship satisfaction and romantic relationship satisfaction are both forms of interpersonal functioning. Therefore, it is reasonable to expect some overlap between the personality predictors of romantic relationship satisfaction and friendship satisfaction. However, there are important differences between the two types of relationships that justify an independent examination of friendship satisfaction. For example, an extravert may be more willing to participate in activities on a weekend, while an introvert is happy staying home. Such a pattern of behaviour may not harm romantic relationship satisfaction but it could be detrimental to friendship satisfaction. Therefore, while research on the personality processes that affect romantic relationship satisfaction is relevant, research specifically looking at predictors of friendship satisfaction is also needed.

Fortunately, there are a few studies that specifically explore the influence of personality on various aspects of friendship. As with romantic relationship satisfaction, agreeableness has proven to be a strong predictor of friendship satisfaction and peer acceptance (Belsky, Jaffee, Caspi, Moffitt, \& Silva, 2003; Demir \& Weitekamp, 2007; Newcomb, Bukowski, \& Pattee, 1993; Stopfer, Egloff, Nestler, \& Back, 2013). Agreeable people are more likely to be selected as friends by others and are less likely to irritate their friends (Berry, Willingham, \& Thayer, 2000; Jensen-Campbell et al., 2002; Lansford, Yu, Pettit, Bates, \& Dodge, 2014). Therefore, we expect agreeableness to be a strong predictor of friendship satisfaction.

Previous research has also established that extraversion is a particularly strong predictor of friendship satisfaction (Jensen-Campbell et al., 2002). Extraverts are known to develop more friendships than introverts, have closer relationships with their friends, be more popular and have higher status among their peers (Asendorpf \& Wilpers, 1998; Berry et al., 2000; Hills \& Argyle, 2001; Jensen-Campbell et al., 2002; Moore \& McElroy, 2012; Ong et al., 2011; Paunonen, 2003; Wilkinson \& Walford, 2001). These results hint at the role extraversion may play in engaging with friends more broadly.

Less is known about the link between the remaining Big Five traits (i.e. conscientiousness, neuroticism and openness) and friendship satisfaction. One study of adolescents found that conscientious students were more likely to have their friendships reciprocated, as well as have better friendship quality (Jensen-Campbell \& Malcolm, 2007). A separate study found a small relationship between conscientiousness and friendship quality (Demir \& Weitekamp, 2007). These results suggest that conscientiousness is worthy of investigation, but its influence is possibly less important for friendships 
than for romantic relationships (Demir \& Weitekamp, 2007; Heller et al., 2004).

Research on neuroticism and friendship satisfaction is surprisingly sparse. Theoretically, neuroticism seems highly relevant for friendship satisfaction, and the limited evidence indicates that this may be the case (Heller et al., 2004; Wilkinson \& Walford, 2001). For example, one daily diary study found that people high in neuroticism experienced more conflict in their friendships than those low in neuroticism (Berry et al., 2000). On the other hand, it is also possible that friendships are less affected by the negative consequences of high neuroticism because perhaps people tend to manifest their neuroticism around romantic partners more often than around their friends (Hirschmüller, Egloff, Schmukle, Nestler, \& Back, 2014; Slatcher \& Vazire, 2009; Vazire, 2010).

Finally, the available evidence indicates that openness is the least influential Big Five predictor of friendship satisfaction, and the direction of any potential effect is unclear (Demir \& Weitekamp, 2007; Jensen-Campbell \& Malcolm, 2007). Because there is little research examining how conscientiousness, neuroticism and openness are related to friendship satisfaction, it is too soon to make strong predictions about the associations between these traits and friendship satisfaction.

\section{Why do certain people have more satisfying friendships?}

Establishing which personality traits predict friendship satisfaction is only the first step in understanding why certain traits lead to better friendship outcomes. As indicated in Figure 1 and outlined in PERSOC, it is necessary to capture the dynamic interpersonal processes unfolding during daily friendship interactions in order to fully understand the factors linking traits and friendship satisfaction. However, choosing the relevant daily variables that may mediate these associations is a formidable task. There are likely hundreds of behavioural, affective and cognitive variables linking personality and friendship satisfaction, and the important mediators may vary depending on the trait. A major goal of the current study is to search for the daily interpersonal processes that might explain why some people have higher friendship satisfaction. Because this is a new area of research, we chose three categories of interpersonal processes that we felt would be the most obvious potential mediators: role personality (specifically, people's Big Five states when they are interacting with their friends), quantity of social interaction and quality of social interaction. The following section briefly describes the theoretical justification for choosing these three categories of potential mediators.

\section{Friendship-role personality}

By definition, global personality traits (e.g. the Big Five) are decontextualised. In other words, any shift in a person's pattern of thoughts, feelings or behaviour because of context is purposefully ignored in order to understand individual differences at the broadest level. However, strong theoretical arguments suggest that systematic shifts based on context may carry important information (Fleeson, 2001; McAdams, 1995; Mischel \& Shoda, 1995). Further, accounting for these shifts in states may increase the ability of personality variables to predict context-specific outcomes such as friendship satisfaction (Slatcher \& Vazire, 2009). The Personality and Q4 Role Identity Structural Model (PRISM) outlines this theoretical perspective, positing that personality is hierarchically structured, with role personality nested under broad personality constructs (Wood, 2007; Wood \& Roberts, 2006). PRISM extends the trait model by accounting for systematic shifts in personality based on context or role. For example, research has shown that people typically act more conscientiously when in the role of 'employee' than when in the role of 'friend' (Donahue \& Harary, 1998). According to PRISM, if you want to predict work outcomes, it makes more sense to ask about personality in the context of work rather than to assess global personality traits, even though people's 'work' personality and 'global' personality are expected to be highly related.

Using the PRISM theoretical model, we predict that people shift their personality patterns when in the presence of friends, and friendship-role personality will be a more proximal predictor of friendship satisfaction than global personality. Thus, friendship-role personality should partially mediate the relationship between global personality and friendship satisfaction. Examining role personality as a potential mediator will tell us whether there is any association between global personality and friendship satisfaction left over when we account for the fact that friendship-role personality likely predicts what people are like around their friends (i.e. their contextualised personality states when interacting with friends), and this may in turn predict friendship satisfaction.

Based on the PRISM framework, we predict that for each global trait that is associated with friendship satisfaction (e.g. global extraversion), the corresponding role personality (e.g. how extraverted a person acts when he or she is with his or her friends) will partially mediate the association between the global trait and friendship satisfaction. To the extent that the direct effect (e.g. of global extraversion on friendship satisfaction, after accounting for the indirect effect through friendship-role extraversion) remains strong, this would suggest that friendship-role personality does not fully explain why global traits are related to friendship satisfaction.

\section{Quantity of social interaction}

Another potential explanation for why personality traits may be associated with friendship satisfaction is that personality may predict how much time people spend with friends, and this may in turn predict friendship satisfaction. In particular, people high in extraversion tend to be more affiliative (Lucas, Diener, Grob, Suh, \& Shao, 2000) and spend less time alone (Mehl, Gosling, \& Pennebaker, 2006). The tendency for extraverts to spend more time with others may then lead to greater friendship satisfaction. Indeed, research suggests that extraverts experience increased positive affect because of their higher quantity of social interaction (Lucas, Le, \& Dyrenforth, 2008; Srivastava, Angelo, \& Vallereux, 2008). If interacting with friends can boost overall affect and satisfaction, then it may also have a similar influence on friendship satisfaction. We explored whether quantity of social 
interactions mediates any of the associations between personality traits and friendship satisfaction. The evidence presented in the literature suggests that this is especially likely to be the case for extraversion; however, we did not make any specific a priori predictions (i.e. we examined quantity of social interaction as a potential mediator of all associations between the Big Five and friendship satisfaction).

\section{Quality of social interaction}

A third possibility is that some people have more satisfying friendships because they have better interactions (not just more interactions) with others. An established body of literature indicates that people who discuss deeper issues, self-disclose information about themselves and avoid emotional suppression have better interpersonal relationships (Ackermam \& Corretti, 2015; Collins \& Miller, 1994; Greene, Derlega, \& Mathews, 2006; Gross, 1998; Gross \& John, 2003; Mehl, Vazire, Holleran, \& Clark, 2010; Tamir \& Mitchell, 2012). In addition, disclosure is often reciprocated, which promotes satisfying interactions and increases liking by others (Collins \& Miller, 1994). In contrast, research has shown that people who consistently suppress their emotions have weaker social connections and receive less social support from friends (English, John, Srivastava, \& Gross, 2012; Srivastava, Tamir, McGonigal, John, \& Gross, 2009). Some of these indicators of interaction quality are in turn associated with personality traits (e.g. low emotion suppression is associated with extraversion, agreeableness and conscientiousness; Gross \& John, 2003). Thus, we predict that the associations between personality traits and friendship satisfaction may be explained, in part, by individual differences in these indicators of quality of interactions (depth of conversation, self-disclosure and low emotion suppression).

\section{Overview of the present hypotheses}

What personality traits predict friendship satisfaction?

The overarching purpose of the present study is to increase our understanding of the mechanisms underlying friendship satisfaction. To begin our investigation, we identify the Big Five personality predictors of friendship satisfaction. We expect our results to be consistent with past research, which indicates that extraversion and agreeableness should be strong predictors of friendship satisfaction. Past research also offers tentative evidence that conscientiousness and (low) neuroticism may be associated with friendship satisfaction but these associations are likely to be weaker than for extraversion and agreeableness.

\section{What friendship processes mediate the associations between traits and friendship satisfaction?}

Although correlations between the Big Five personality traits and friendship satisfaction will shed some light on who is more satisfied with their friendships, they cannot tell us much about why some people are more satisfied than others. To answer this question, we will examine how processes relevant to friendship interactions are associated with friendship satisfaction and whether these more proximal variables may account for some of the associations between the Big Five and friendship satisfaction. Based on the PERSOC and PRISM models reviewed earlier, we predict that friendshiprole personality, quantity of social interaction and quality of social interaction will predict friendship satisfaction and will account for (i.e. mediate) some of the associations between personality traits and friendship satisfaction.

\section{METHOD}

The current investigation is part of the longitudinal Personality and Interpersonal Roles Study (PAIRS; Vazire et al., 2015). The data used in the current analyses are taken from the initial wave of data collection. This is the first published manuscript using the PAIRS dataset. We report how we determined our sample size, all data exclusions and all measures examined as part of this project (Simmons, Nelson, \& Simonsohn, 2012; see https://osf.io/jsa5k for additional details regarding data and other measures collected in PAIRS).

\section{Participants}

Participants $(N=434)$ were students recruited via a psychology participant pool, flyer advertisements and classroom announcements at a private Midwestern Eniversity in the USA. We stopped data collection when we reached the end of a semester and had recruited at least 400 participants. Of the 434 participants who completed the initial session of PAIRS, 378 completed all measures relevant for the current study, and only this subset will be used in the present analyses. Participants $(68 \%$ female) ranged in age from 18 to 32 $(M=19.3, S D=2.0)$ were paid $\$ 20$ for the in-lab portion of the first assessment and were entered into a lottery with the opportunity to win $\$ 100$ for completing ecological momentary assessment (EMA SO veys, which will be described in detail in the following (une odds of winning were 1 in 10 if all EMA surveys were completed).

\section{Procedure}

The first portion of the study involved a two-hour lab session in which participants completed a variety of personality questionnaires as well as a range of other tasks not related to the current study. During the lab session, we also asked participants to nominate up to six friends to rate their personality: best friend, roommate or local friend, hometown friend, friend of the opposite sex and two additional friends. If nominated, these peers were emailed a survey and asked to rate the participant's personality (see Vazire, 2006 for details about the method). A total of 918 friends provided ratings of participants' personalities $(M=2.43$ friend per target, $S D=1.28)$.

At the conclusion of the in-lab session, the EMA portion of the study began. Participants were emailed surveys four times a day for just over 14 days, for a total of 59 possible surveys per participant. This repeated-measures design was implemented to provide an ecologically valid measure of personality states and behaviour as they occurred in 
approximately real time (Mehl \& Conner, 2011). Participants were asked to rate how they were thinking, feeling and behaving during a specified hour block (e.g. 'From 11 AM to 12 PM,...$')$. These surveys were emailed to participants at exactly 12, 3, 6 and 9PM using Qualtrics, a survey design programme. Text messages were also sent to participants' phones at these times as a reminder to complete the surveys.

The EMA surveys took 3-4 minutes to complete and could be taken on a smartphone or any other device with access to the Internet. One concern was that participants with smartphones $(71.8 \%)$ would complete more EMA surveys than those without smartphones, but, surprisingly, no significant association was found between having a smartphone and number of EMA surveys completed $(r=-.04, p=.54)$.

The surveys asked participants to report on personality states (eight items, e.g. 'rude' and 'reliable'), situational information (six items, e.g. alone or around others), interpersonal behaviours (if they indicated they were around others; six items, e.g. 'how deep/substantive was the conversation?'), mood (six items, e.g. 'happy' and 'lonely') and other behavioural items, including a checklist indicating whether the person/people they were interacting with were friends (26 items; see Appendix A for full survey).

Participants completed a total of 15563 EMA surveys. To ensure a high level of quality for the EMA data, a number of exclusion criteria were enforced. These exclusion criteria were determined prior to analysing the data. Specifically, EMA surveys were excluded from analysis if (i) a survey was completed more than three hours after it was sent; (ii) the participant indicated that they were sleeping during the hour block; (iii) less than $75 \%$ of the items on the survey were completed; or (iv) if the participant gave the same response for $70 \%$ or more of the items. Based on these strict criteria, 11591 surveys qualified for inclusion (74.5\%; $M=29.7, S D=15.2$ ). The EMA surveys provide the contextualised personality measures and behavioural measures necessary for assessing the mediators in our models.

\section{Measures}

\section{Trait personality}

To reduce the amount of method overlap between our measures of trait personality and friendship satisfaction, we used a composite of self-ratings and peer-ratings of personality (see Appendix B for associations between self, friends and self-friends composite variables). Participants and friends rated participants' personalities using the Big Five Inventory (BFI-44; John \& Srivastava, 1999) on a 15-point Likert-type scale. The agreement between self-ratings of personality and averaged friend ratings of personality was relatively high (extraversion $r=.65$; agreeableness, $r=.48$; consciousness, $r=.50$; neuroticism, $r=.53$; openness, $r=.46$ ). Self and friend ratings of personality were aggregated into a composite by weighting the self-reports as much as each individual T1 friend report (see Table 1 for reliabilities).

For the regression and meditational analyses presented in T4 T3 T2 Tables 2 through 4, we used structural equation modelling to create latent variables based on self and friend ratings for each Big Five trait using Lavaan, a statistical package in $\mathrm{R}$
(Rosseel, 2012). We tested various models for different levels of measurement invariance and determined that in the best fitting models, the factor loading for self-report was allowed to freely vary, while the loadings for the friend reports were constrained to be equal. To account for missing data from friends who did not fill out the questionnaire, full information maximum likelihood estimation was used (Enders \& Bandalos, 2001).

\section{Friendship-role personality}

The EMA surveys included items that assessed personality states, which we used to measure friendship-role personality. We created a shortened version of the BFI-44 to measure each Big Five construct at the state level. The shortened BFI scale was composed of two items per Big Five construct taken from the original BFI-44, making sure that each item (i) made sense at the state level, (ii) assessed a different facet of the respective Big Five construct, (iii) avoided difficult vocabulary words, and (iv) had a comparatively high item total correlation (Appendix A). The item stems were changed to refer to the specific time period covered by the EMA survey (e.g. 'From 2-3 PM, how lazy were you?') and responses were given on a five-point Likert-type scale. However, we did not include EMA items for the Big Five construct of openness because at the time of designing the study, we did not feel that these items could be easily understood as personality states ('has few artistic interests' and 'has an active imagination'). ${ }^{1}$ Thus, the EMA surveys measured personality states for four of the Big Five personality dimensions while remaining as brief as possible to maintain an acceptable response rate.

To compute friendship-role personality measures for each participant, we aggregated his or her EMA responses to the items corresponding to each Big Five construct, including only surveys completed when the participant indicated she or he was interacting with a friend $(M=37 \%$ of surveys, $S D=19 \%$ ). Although the nesting of friendship interactions within-person may suggest a multilevel analysis, aggregation of EMA personality is a preferable analytic method for assessing between-person differences in role-based personality, as outlined by the PRISM model (Ching et al., 2013). Internal reliability for the Big Five EMA composites was acceptable given that each construct was assessed with only two items (extraversion $\alpha=.83$, agreeableness $\alpha=.43$, conscientiousness $\alpha=.69$, neuroticism $\alpha=.83$ ). For our initial correlational results (Table 1), we used these aggregated Big Five composites as a measure of friendship-role personality. For our regression and meditational analyses (Tables 2-4), we used structural equation modelling to create latent variables for each friend-role personality construct. The loadings for both indicators were constrained to be equal.

\section{Quantity of friendship interactions}

To measure the quantity of friendship interactions, we calculated the percentage of EMA files in which each participant

\footnotetext{
${ }^{1}$ We have since changed our minds. We believe capturing state openness with EMA surveys is achievable and now include these measures in our ongoing research.
} 


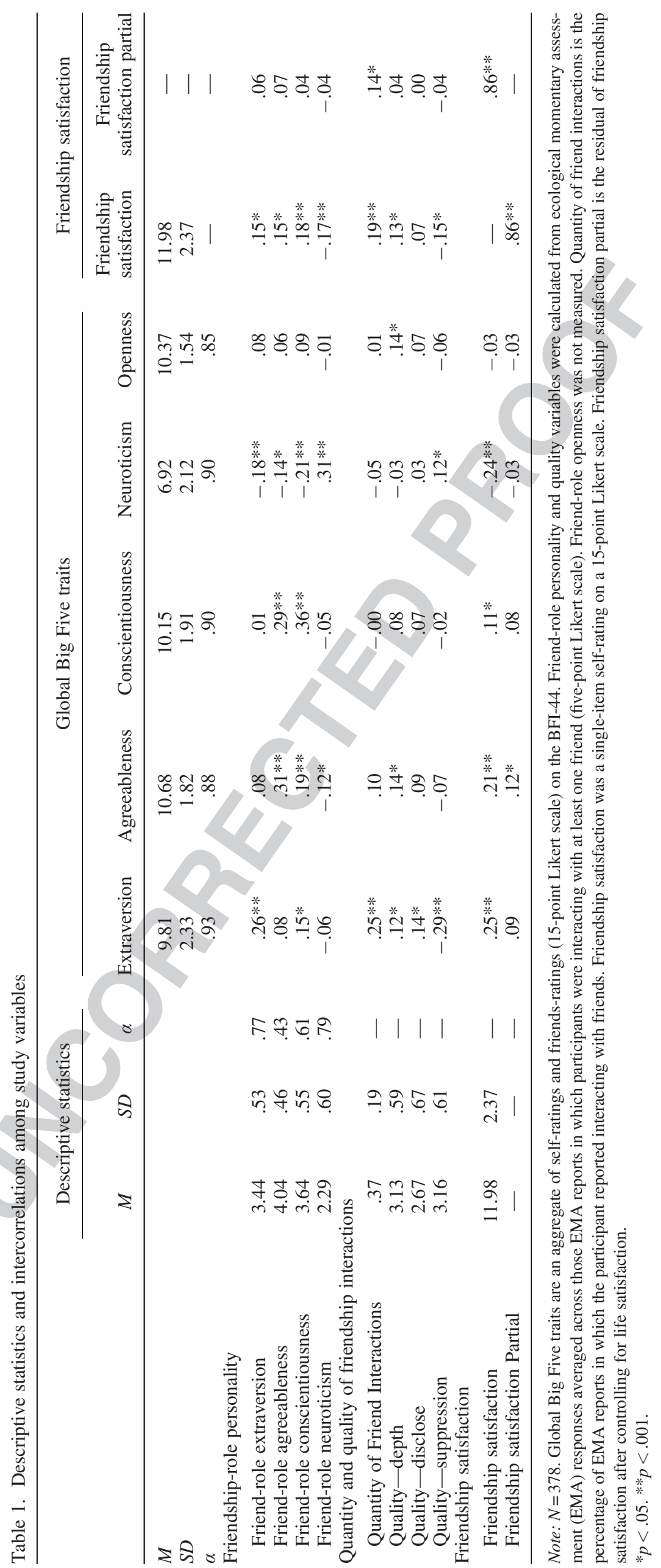


Table 2. Multiple predictors of friendship satisfaction entered simultaneously

\begin{tabular}{lc}
\hline & Friendship satisfaction \\
\hline Model 1. Global Big Five & $\beta$ \\
Extraversion & $.25^{* *}$ \\
Agreeableness & $.20^{* *}$ \\
Conscientiousness & $.13^{*}$ \\
Neuroticism & $-.16^{*}$ \\
Openness & -.04 \\
Model 2. Friend-role Big Five & .07 \\
Friend-role extraversion & .02 \\
Friend-role agreeableness & $.13^{*}$ \\
Friend-role conscientiousness & $-.13^{*}$ \\
Friend-role neuroticism & $.17^{* *}$ \\
Model 3. Quantity and quality & $.14^{*}$ \\
Quantity of social interaction & -.02 \\
Quality—depth of conversation & -.10 \\
Quality—disclose information & \\
Quality—emotional suppression &
\end{tabular}

Note: $N=378$. All betas are standardised. The dependent variable in all models was self-rated friendship satisfaction. Model 1 is a structural equation model in which predictors were latent variables. Models 2 and 3 are multiple regressions in which predictors were composites based on ecological momentary assessment reports averaged across those reports in which the participant was interacting with a friend.

$* p<.05 . * * p<.001$.

reported interacting with one or more friends. Of the 11591 surveys, participants interacted with a friend in 3689 of the EMA surveys, with the average participant interacting with friends $37 \%$ of the time, although there was a great deal of between-person variability $(S D=19 \%)$.

\section{Quality of friendship interactions}

To measure the behaviours relevant to quality of interactions with friends we included three items: 'How superficial (i.e. shallow) to substantive (i.e. deep) were the conversations?', 'How much did you self-disclose?', and 'Did you keep your emotions to yourself?'. All items were rated on a five-point Likert-type scale (Appendix A). These three items are intended to indicate the overall quality of each interaction with friends, but they are not meant to be a definitive list of all variables associated with friendship interaction quality. To compute a measure of these constructs for each participant, we aggregated his or her EMA responses for each of these items when the participant indicated she or he was interacting with a friend $(M=37 \%$ of surveys, $S D=19 \%)$. The item 'Did you keep your emotions to yourself?' was adapted from the Emotional Regulation Questionnaire and is an indicator of emotional suppression (ERQ; Gross \& John, 2003). These three constructs are correlated (disclose-suppression, $\quad r=-.23$; disclose-depth, $\quad r=.47$; depth-suppression, $r=-.12$ ), and conceptually, they are all related to the quality of friendship interactions. However, because the correlations among the constructs are only moderate and because they assess slightly different processes, we report the results separately for each construct.

\section{Friendship satisfaction and life satisfaction}

During the initial lab session, participants completed a single-item measure of friendship satisfaction ('How satisfied are you with your friendships?'), which we used as the dependent variable in Tables 1-4. Participants also completed a single-item measure of life satisfaction ('How

Table 3. Personality traits and daily friendship behaviours predicting friendship satisfaction

\begin{tabular}{|c|c|c|c|c|c|c|}
\hline & \multicolumn{2}{|c|}{ Friendship satisfaction } & \multicolumn{4}{|c|}{ Model fit } \\
\hline & Predictor variables & $\beta$ & $X^{2}$ & CFI & TLI & RMSEA \\
\hline Model 1 & $\begin{array}{l}\text { Global extraversion } \\
\text { Friend-role extraversion }\end{array}$ & $\begin{array}{l}.24 * * \\
.09\end{array}$ & $61.44 *(39,378)$ & 0.965 & 0.960 & 0.039 \\
\hline Model 2 & $\begin{array}{l}\text { Global extraversion } \\
\text { Quantity of social interactions }\end{array}$ & $\begin{array}{l}.24 * * \\
.14 * *\end{array}$ & $83.10 *(32,378)$ & 0.889 & 0.875 & 0.065 \\
\hline Model 3 & $\begin{array}{l}\text { Global extraversion } \\
\text { Depth of conversation }\end{array}$ & $\begin{array}{l}.26^{* *} \\
.10^{*}\end{array}$ & $63.31 *(32,378)$ & 0.929 & 0.920 & 0.051 \\
\hline Model 4 & $\begin{array}{l}\text { Global extraversion } \\
\text { Self-disclosure }\end{array}$ & $\begin{array}{l}.27 * * \\
.04\end{array}$ & $59.48 *(32,378)$ & 0.936 & 0.928 & 0.048 \\
\hline Model 5 & $\begin{array}{l}\text { Global extraversion } \\
\text { Suppression }\end{array}$ & $\begin{array}{l}.25^{* * *} \\
-.09\end{array}$ & $86.94 *(32,378)$ & 0.881 & 0.866 & 0.067 \\
\hline Model 6 & $\begin{array}{l}\text { Global agreeableness } \\
\text { Friend-role agreeableness }\end{array}$ & $\begin{array}{l}.23 * * \\
.09\end{array}$ & $105.71 *(39,378)$ & 0.815 & 0.787 & 0.067 \\
\hline Model 7 & $\begin{array}{l}\text { Global agreeableness } \\
\text { Depth of conversation }\end{array}$ & $\begin{array}{l}.26^{* *} \\
.10\end{array}$ & $63.37 *(32,378)$ & 0.883 & 0.868 & 0.051 \\
\hline Model 8 & $\begin{array}{l}\text { Global conscientiousness } \\
\text { Friend-role conscientiousness }\end{array}$ & $\begin{array}{l}-.03 \\
.26 * *\end{array}$ & $64.05 *(39,378)$ & 0.937 & 0.927 & 0.041 \\
\hline Model 9 & $\begin{array}{l}\text { Global neuroticism } \\
\text { Friend-role neuroticism }\end{array}$ & $\begin{array}{l}-.27 * * \\
-.09\end{array}$ & $49.9(39,378)$ & 0.981 & 0.978 & 0.026 \\
\hline Model 10 & $\begin{array}{l}\text { Global neuroticism } \\
\text { Suppression }\end{array}$ & $\begin{array}{l}-.29 * * \\
-.12 *\end{array}$ & $44.00(32,378)$ & 0.958 & 0.953 & 0.031 \\
\hline
\end{tabular}

Note: $N=378$. The dependent variable in all models was self-rated friendship satisfaction. All predictor variables in each model were entered simultaneously in SEM models using latent variables. See Table 1 for descriptions of each variable and raw associations. The second row in each model corresponds to path $\mathrm{b}$ in Figure 1. These models were selected based on the criteria for mediation and the results from Table 1 (see Results section for explanation). CFI, comparative fit index; TLI, Tucker-Lewis index; RMSEA, root mean square error of approximation.

$* p<.05 . * * p<.001$. 
Table 4. Mediation models: daily friendship interaction variables as mediators of the association between personality traits and friendship satisfaction

\begin{tabular}{|c|c|c|c|c|c|c|c|c|c|c|c|}
\hline & \multicolumn{4}{|c|}{ Model fit } & \multirow{2}{*}{$\frac{\text { Path a }}{\beta}$} & \multirow{2}{*}{$\begin{array}{c}\text { Path b } \\
\beta\end{array}$} & \multirow{2}{*}{$\begin{array}{c}\text { Path c } \\
\qquad \beta\end{array}$} & \multirow{2}{*}{$\begin{array}{c}\text { Path } \mathrm{c}^{\prime} \\
\beta\end{array}$} & \multirow{2}{*}{$\frac{\text { Indirect }}{\beta}$} & \multicolumn{2}{|c|}{$95 \% \mathrm{CI}$} \\
\hline & $X^{2}$ & CFI & TLI & RMSEA & & & & & & Lower & Upper \\
\hline $\begin{array}{l}\text { IV: Global extraversion } \\
\text { Mediator: quantity of } \\
\text { social interactions }\end{array}$ & $61.27 *(31,378)$ & 0.934 & 0.924 & 0.051 & $.27 * *$ & $.13 *$ & $.27 * *$ & $.24 * *$ & $.03 *$ & .004 & .069 \\
\hline $\begin{array}{l}\text { IV: Global extraversion } \\
\text { Mediator: depth of } \\
\text { conversation }\end{array}$ & $56.861 *(31,378)$ & 0.941 & 0.931 & 0.047 & $.15^{*}$ & .09 & $.28 * *$ & $.26^{* *}$ & .01 & -.002 & .034 \\
\hline $\begin{array}{l}\text { IV: Global conscientiousness } \\
\text { Mediator: friend-role } \\
\text { conscientiousness }\end{array}$ & $64.05 *(39,378)$ & 0.937 & 0.927 & 0.041 & $.59 * *$ & $.26 * *$ & .12 & -.03 & $.14 *$ & .022 & .323 \\
\hline $\begin{array}{l}\text { IV: Global neuroticism } \\
\text { mediator: suppression }\end{array}$ & $38.98(31,378)$ & 0.972 & 0.968 & 0.026 & $.14^{*}$ & $-.11^{*}$ & $-.30 * *$ & $-.29 * *$ & -.02 & -.038 & .000 \\
\hline
\end{tabular}

Note.

Note: $N=378.5000$ bootstrap samples. The dependent variable in all models was self-rated friendship satisfaction. See Table 1 for descriptions of each variable and raw associations. These models were selected based on the criteria for mediation and the results from Tables 1 and 3 (see Results section for explanation). Paths a, b, c and $\mathrm{c}^{\prime}$ correspond to Figure 1 .

CFI, comparative fit index; TLI, Tucker-Lewis index; RMSEA, root mean square error of approximation.

$* p<.05$. ** $p<.001$.

satisfied are you with your life?'). While the focus of the current study is on friendship satisfaction, we also examined what the associations among the variables in our study look like when we partial out life satisfaction from friendship satisfaction ratings (see bottom row and last column of Table 1).

\section{RESULTS}

First, we examined the correlations between the Big Five personality traits and friendship satisfaction (second to last row of Table 1). Our results indicate that extraversion was the strongest predictor of friendship satisfaction $(r=.25$, $p<.001)$, followed by neuroticism $(r=-.24, p<.001)$, agreeableness $(r=.21, p<.001)$ and conscientiousness $(r=.11, p=.04)$. As predicted, openness was not associated with friendship satisfaction $(r=-.03, p=.55)$. As an additional way to assess the relative strength of each Big Five predictor, we used structural equation modelling to examine the associations with friendship satisfaction when all Big Five personality traits were included in the same model (see Table 2, model $1 ; X^{2}(535, N=378)=1389.82$, $p<.05)$. The results of this analysis reflect a similar pattern as indicated by the raw correlations in Table 1 . Thus, on average, the people who tend to be the most satisfied with their friendships are more extraverted, agreeable, emotionally stable and conscientious than people who are dissatisfied with their friendships. This is mostly consistent with our predictions, although we did not expect neuroticism to emerge as such a strong predictor.

Second, we assessed the strength of the friendship-role personality variables as predictors of friendship satisfaction relative to the general personality measures. Based on PRISM, we expected friendship-role personality to be a stronger predictor of friendship satisfaction than general trait personality is. The results in Table 1 revealed that this assumption was only true for friendship-role conscientiousness $(r=.18, p<.001)$. The other friendship-role predictors remained significant but were weaker than the corresponding trait measure (friendship-role extraversion, $r=.15, p=.003$; friendship-role agreeableness, $r=.15, p=.003$; friendshiprole neuroticism, $r=-.17, p=.001$ ).

Table 1 also includes the associations between the Big Five and the variable that was created by residualising participants' friendship satisfaction scores on their life satisfaction scores ('Friendship Satisfaction Partial', bottom row of Table 1). We examined how the Big Five are associated with this variable because this gives us an idea of how personality is uniquely related to friendship satisfaction, after accounting for the overlap between friendship satisfaction and life satisfaction $(r=.86, p<.001)$. As these results show, all of the associations between the Big Five and this new variable are substantially weaker than the associations between the Big Five and friendship satisfaction. Indeed, the associations mostly become non-significant (although we do not have sufficient power to detect effects smaller than $|r|=.10$ ), and the association between neuroticism and this new variable is very close to zero. However, these analyses are an extremely conservative test of the association between the Big Five and friendship satisfaction, as much of the overlap between friendship satisfaction and life satisfaction is valid variance in friendship satisfaction. Thus, partialling life satisfaction from friendship satisfaction helps us gain a better understanding of the nature of the associations between personality and friendship satisfaction, but the correlations with the raw friendship satisfaction variable (second row from bottom in Table 1) are better estimates of these associations (note that it is not common to see this kind of analysis in the relationship satisfaction literature).

Recall that four of the Big Five traits showed significant associations with friendship satisfaction, so we will examine potential mediators of each of these four associations separately. However, we first needed to identify whether any of the interpersonal variables we examined could potentially 
be mediators for each of four models. To do this, we needed to identify which of these potential mediators both (i) were associated with the global trait of interest (path a) and (ii) predicted unique variance in friendship satisfaction above and beyond the global trait (path b; Baron \& Kenny, 1986; Kenny, Kashy, \& Bolger, 1998).

Table 1 includes all of the associations among the Big Five traits and the potential mediators ('friendship-role personality' and 'quantity and quality of friendship interactions'). For the friendship-role variables, we only considered as potential mediators friendship-role variables that match the global trait construct (e.g. friendship-role extraversion was considered as a potential mediator of the association between global extraversion and friendship satisfaction, but none of the other friendship-role variables were considered). As Table 1 shows, trait extraversion was correlated with all of the potential mediators: friendship-role extraversion, quantity of social interaction and all three measures of quality of social interaction. Trait agreeableness was associated with friendship-role agreeableness and with depth of conversation, but not quantity of social interaction, disclosure or emotion suppression. Trait conscientiousness was only correlated with friendship-role conscientiousness. Trait neuroticism is only correlated with friendship-role neuroticism and emotion suppression. We did not examine the correlations between global openness and potential mediators because global openness was not associated with friendship satisfaction. (Note that Table 2, model 2 also shows the unique predictive validity of each friendship-role personality construct when they are all included in the same model, and Table 2, model 3 shows the unique predictive validity of the interpersonal behaviours when they are all included in the same model).

Returning to the mediation models, the next step was to examine, for each pair of global trait and potential mediator for which there was a significant correlation, whether the potential mediator met the next step for mediation: did it predict friendship satisfaction above and beyond the global trait? To test this, we ran separate models for each global trait-potential mediator pair (10 regressions) using structural equation modelling. The results of these analyses along with model fit indices are presented in Table 3.

Only a few of the potential mediators were significant unique predictors of friendship satisfaction. Specifically, for global extraversion, only quantity of social interaction and depth of conversation qualified as potential mediators [i.e. both had a significant path a (Table 1) and path $b$ (Table 3)]. For global agreeableness, no variables qualified as a potential mediator. For global conscientiousness, only friendship-role conscientiousness qualified as a potential mediator. For neuroticism, only emotion suppression qualified as a potential mediator.

Finally, we tested the full mediation models for each of these four pairs of global traits and potential mediators (Table 4). Specifically, we used structural equation modelling to estimate the indirect effects $(a * b)$ using bootstrap estimation with reported confidence intervals (5000 iterations; MacKinnon, Fritz, Williams, \& Lockwood, 2007; Preacher \& Hayes, 2004; Preacher \& Hayes, 2008). As shown in
Table 4, only two of the indirect effects were significant. Specifically, quantity of social interaction partially mediated the association between trait extraversion and friendship satisfaction, and friendship-role conscientiousness fully mediated the association between global conscientiousness and friendship satisfaction.

\section{DISCUSSION}

\section{Trait-friendship satisfaction link}

The results presented in Tables 1 and 2 provide a strong basis for several general conclusions. First, personality predicts friendship satisfaction, which is further evidence for the social consequences of personality. Previous research has demonstrated that personality predicts outcomes in the health, romantic and occupational domains (Roberts et al., 2007), and these results provide further evidence that personality also predicts another important outcome: friendship satisfaction. This suggests that friendships deserve more attention from personality psychologists.

Consistent with our predictions, extraversion and agreeableness were both associated with greater friendship satisfaction. Contrary to our predictions, neuroticism was also strongly (negatively) correlated with friendship satisfaction. Conscientiousness was significantly associated with higher friendship satisfaction, although this correlation was descriptively weaker. Not surprisingly, openness was not correlated with friendship satisfaction. All of the associations became weaker when life satisfaction was partialled out of friendship satisfaction, a finding that simply reflects the strong overlap between friendship satisfaction and life satisfaction. Finally, as the results in Table 2 show, all of the associations between the Big Five and friendship satisfaction are relatively independent of each other-most of them are still substantial when all five traits are entered simultaneously as predictors of friendship satisfaction.

The pattern of correlations between the Big Five and friendship satisfaction is slightly different from the patterns found in previous research on personality and romantic relationship satisfaction (Heller et al., 2004). There is not only some overlap with the known associations between the Big Five and romantic relationship satisfaction (e.g. these results suggest that agreeableness and neuroticism are important predictors of both friendship and romantic relationship satisfaction) but also important differences (e.g. these results suggest that extraversion may be more important for friendship satisfaction than for romantic relationship satisfaction, and the reverse may be true for conscientiousness). It is likely that the processes (cognitive, affective and behavioural) that lead to satisfying friendships are also overlapping but distinct from the processes that lead to romantic relationship satisfaction.

\section{Personality and daily friendship interactions}

Before discussing the mediation models, we would like to pause and reflect on the associations between global trait measures of personality and our measures of friendship-role 
personality and friendship-related processes (Table 1). This pattern of correlations is interesting in and of itself, even without including friendship satisfaction in the picture. First, we replicated the by-now-well-established finding that global personality traits are strongly correlated with average personality states (Fleeson \& Gallagher, 2009). However, we have extended this finding by showing that global personality traits predict average states in a particular role (in this case, with friends). Future research should examine whether global personality predicts contextualised average states across a range of roles/contexts and whether some contexts are more strongly associated with global personality than others (e.g. are people more like their 'global selves' when interacting with those they like than when interacting with those they dislike?).

Second, it is interesting to note that, of the global Big Five traits, only extraversion is associated with spending more time interacting with friends ('quantity of social interaction'). Agreeable people do not spend more time with friends than disagreeable people, and neurotic people do not spend less time with friends than emotionally stable people. This is consistent with existing literature showing that extraversion is associated with a stronger need for affiliation (Lucas et al., 2000).

Third, the associations among the Big Five and our indicators of quality of social interaction (depth of conversation, disclosure and emotion suppression) also provide some food for thought. Overall, extraversion and agreeableness seem to be the most strongly associated with higher quality interactions. However, because the 'quality of interaction' variables were self-reported, it is possible that some of these associations are due to self-report biases. Future research should examine whether people higher in extraversion and agreeableness do in fact have deeper conversations including more self-disclosure and emotion expression, for example, by using observer-based measures of depth of conversation, self-disclosure and emotion expression (e.g. Mehl, Pennebaker, Crow, Dabbs, \& Price, 2001; Zalk, Zalk, Kerr, \& Stattin, 2014).

\section{Mediation analyses}

Considering (i) the exploratory nature of the analyses we conducted, (ii) the large number of potential mediation models we considered ( 4 predictors $\times 5$ mediators $=20$ potential indirect effects), (iii) the relatively small number that met the criteria for mediation (paths a and b significant: 4 out of 20), and (iv) the relatively small effect sizes for the indirect effects examined, we are reluctant to draw specific conclusions from the mediation results. There are some hints that these daily states and behaviours may help account for some of the associations between global traits and friendship satisfaction. In particular, one of the significant mediation models (first row of Table 4) is very consistent with existing theory and research on extraversion-it is not surprising that extraverts spend more time with friends and that this, in part, accounts for their higher friendship satisfaction. However, the indirect effect is quite small, and the direct effect (path $\mathrm{c}^{\prime}$ ) is not much smaller than the total effect (path c).
The other significant mediation model (third row of Table 4) is less obviously consistent with personality theory, but it is a substantially larger effect. Overall, the vast majority of the shared variance between traits and friendship satisfaction remains unaccounted for. While we encourage researchers to test the replicability of the two significant mediation models in Table 4, we refrain from interpreting them further.

There are a few potential explanations for the overall weak mediation results. First, it is possible that our measures of friendship-role personality, quantity of social interaction and quality of social interaction were poor measures of these constructs. However, although these measures, like all measures, are imperfect, we believe the EMA approach is a sound one for measuring these constructs, and there are no indications in our data that suggest that our assessment of these constructs was invalid. Alternatively, it might be the case that the lack of large meditation effects may represent reality - the interpersonal behaviours we examined may not be responsible for the associations between personality traits and friendship satisfaction. Such a conclusion seems reasonable given the current results. However, it is almost necessarily true that some kinds of interpersonal process must mediate the association between personality and friendship satisfaction. Therefore, we suspect that our lack of meditation effects is due to the complex nature of friendship satisfaction-there are likely many proximal causes of friendship satisfaction, and these proximal causes likely interact with and influence one another (Hagemeyer, Neyer, Neberich, \& Asendorpf, 2013). As predicted by PERSOC theory, these causes of friendship satisfaction likely include: the traits of actors, actors' behaviours, partners' perceptions of those behaviours, partners' behaviours, actors' perceptions of partners' behaviours, and more. Because the analyses in the current study were cross-sectional, we were unable to reach firm conclusions regarding the direction and flow of these processes. Our results justify more complex longitudinal research designs in the future in order to capture these dynamic interdependent processes (Back \& Vazire, in press, this volume; Vater \& Schroder-Abe, 2015).

\section{Future directions and conclusion}

As mentioned earlier, little research exists on friendship satisfaction. We encourage researchers to continue examining the interplay among personality, interpersonal processes and friendship satisfaction in different populations. While college students are an ideal population in which to study friendship formation, dissolution and interaction quality, some correlates and processes may be unique to this demographic. For example, it is possible that different personality traits predict friendship satisfaction in middle or late adulthood, when people's environments are more stable. Alternatively, it is possible that the personality correlates remain the same, but the underlying processes change (e.g. perhaps extraverts are more satisfied with their friendships throughout the lifespan but for different reasons at different times). The same applies to other group differences, such as culture, social class or ethnicity. By understanding the processes that account for individual differences in friendship satisfaction 
in different groups, we can better help people understand what may promote or impede the development of quality friendships.

Another understudied topic is the role that friendship satisfaction plays in overall life satisfaction. While there have been excellent studies of the relationship between domain satisfaction and life satisfaction (Heller et al., 2004; Helliwell et al., 2013), few of these studies include friendship satisfaction as a facet. However, our results suggest that there are important individual differences in friendship satisfaction and that these differences may be due to stable personality differences. Understanding how satisfaction with one's friendships impacts overall life satisfaction could shed light on the role that friendship plays in well-being. For example, it is possible that the association between friendship satisfaction and life satisfaction is moderated by age or even by personality traits. This would suggest that friendship satisfaction matters more for well-being at different times in life or for different people.

Another promising avenue for future research is using EMA to measure role personality (i.e. including only personality states reported when in a specific role or situation; e.g. Ching et al., 2013). This approach allows researchers to capture a theoretically and methodologically rich construct (i.e. what people are like in a particular role as reported in real time) and presents an especially promising and underutilised method for operationalising role personality.

Finally, future studies should distinguish between friends and other personal relationships and their associated behavioural processes in order to understand the contribution each makes to overall life satisfaction. When the assessment of friendship quality is lumped together with other forms of social support such as satisfaction with co-workers, family and romantic relationships, it is difficult to discern the effects of specific processes unique to each of these relationships. Examining the processes that influence all close relationships is important, but there are also important differences among different types of close relationships. For example, unlike other social relationships, friendships affect everyone (whether or not they have a spouse or a job) and endure across the entire lifespan. In addition, the patterns of behaviour that determine friendship quality begin early in life and likely influence future relationships such as romantic relationships and work relationships. Therefore, we hope that future work will continue to disentangle the individual differences and interpersonal processes that underlie friendship satisfaction.

\section{REFERENCES}

Ackermam, R., \& Corretti, C. (2015). Pathological personality traits and intimacy processes within roommate relationships. European Journal of Personality, 'THIS ISSUE; INSERT CORRECT PAGE NUMBERS WHEN DETERMINED'.

Asendorpf, J. B., \& Wilpers, S. (1998). Personality effects on social relationships. Journal of Personality and Social Psychology, 74, 1531-1544.

Back, M. D., Baumert, A., Denissen, J. J. A., Hartung, F. M., Penke, L., Schmukle, S. C.,...Wrzus, C. (2011). PERSOC: A unified framework for understanding the dynamic interplay of personality and social relationships. European Journal of Personality, 25, 90-107.

Back, M. D., \& Vazire, S. (in press, this volume). The social consequences of personality: Six suggestions for future research. European Journal of Personality, 'THIS ISSUE; INSERT CORRECT PAGE NUMBERS WHEN DETERMINED'.

Baron, R. M., \& Kenny, D. A. (1986). The moderator-mediator variable distinction in social psychological research: Conceptual, strategic, and statistical considerations. Journal of Personality and Social Psychology, 51, 1173-1182.

Belsky, J., Jaffee, S. R., Caspi, A., Moffitt, T., \& Silva, P. A. (2003). Intergenerational relationships in young adulthood and their life course, mental health, and personality correlates. Journal of Family Psychology, 17, 460-471.

Berry, D. S., Willingham, J. K., \& Thayer, C. A. (2000). Affect and personality as predictors of conflict and closeness in young adults' friendships. Journal of Research in Personality, 34, 84-107.

Buote, V. M., Pancer, S. M., Pratt, M. W., Adams, G., Birnie-Lefcovitch, S., Polivy, J., \& Wintre, M. G. (2007). The importance of friends friendship and adjustment among 1st-year university students. Journal of Adolescent Research, 22, 665-689.

Ching, C. M., Church, A. T., Katigbak, M. S., Locke, K. D., Vargas-Flores, J., Ibanez-Reyes, J.,... Ortiz, F. A. (2013). Crosscultural generalizability of the personality and role identity structural model (PRISM): Implications for trait and cultural psychology. Journal of Research in Personality, 47, 894-907.

Collins, N. L., \& Miller, L. C. (1994). Self-disclosure and liking: A meta-analytic review. Psychological Bulletin, 116, 457-475.

Demir, M., \& Weitekamp, L. A. (2007). I am so happy cause today I found my friend: Friendship and personality as predictors of happiness. Journal of Happiness Studies, 8, 181-211.

Diener, E., \& Lucas, R. E. (1999). Personality and subjective wellbeing. In D. Kahneman, E. Diener, \& N. Schwarz (Eds.), Wellbeing: The foundations of hedonic psychology (pp. 213-229). New York: Russell Sage Foundation.

Donahue, E. M., \& Harary, K. (1998). The patterned inconsistency of traits: Mapping the differential effects of social roles on selfperceptions of the Big Five. Personality and Social Psychology Bulletin, 24, 610-619.

Enders, C. K., \& Bandalos, D. L. (2001). The relative performance of full information maximum likelihood estimation for missing data in structural equation models. Structural Equation Modeling, 8, 430-457.

English, T., John, O. P., Srivastava, S., \& Gross, J. J. (2012). Emotion regulation and peer-rated social functioning: A 4-year longitudinal study. Journal of Research in Personality, 46, 780-784.

Fleeson, W. (2001). Toward a structure-and process-integrated view of personality: Traits as density distributions of states. Journal of Personality and Social Psychology, 80, 1011-1027.

Fleeson, W., \& Gallagher, P. (2009). The implications of Big Five standing for the distribution of trait manifestation in behavior: Fifteen experience-sampling studies and a meta-analysis. Journal of Personality and Social Psychology, 97, 1097-1114.

Finn, C., Mitte, K., \& Neyer, F. J. (2013). The relationship-specific interpretation bias mediates the link between neuroticism and satisfaction in couples. European Journal of Personality, 27, 200-212.

Greene, K., Derlega, V. J., \& Mathews, A. (2006). Self-disclosure in personal relationships. The Cambridge handbook of personal relationships, 409-427.

Gross, J. J. (1998). Antecedent-and response-focused emotion regulation: Divergent consequences for experience, expression, and physiology. Journal of Personality and Social Psychology, 74, 224.

Gross, J. J., \& John, O. P. (2003). Individual differences in two emotion regulation processes: Implications for affect, relationships, and well-being. Journal of Personality and Social Psychology, 85, 348-362.

Hagemeyer, B., Neyer, F. J., Neberich, W., \& Asendorpf, J. B. (2013). The ABC of social desires: Affiliation, being alone, 
andcloseness to partner. European Journal of Personality, 27, 442-457.

Heller, D., Watson, D., \& Ilies, R. (2004). The role of person versus situation in life satisfaction: A critical examination. Psychological Bulletin, 130, 574-600.

Helliwell, J. F., Layard, R., \& Sachs, J. (Eds.). (2013). World happiness report 2013. Sustainable Development Solutions Network.

Hills, P., \& Argyle, M. (2001). Emotional stability as a major dimension of happiness. Personality and Individual Differences, $31,1357-1364$.

Hirschmüller, S., Egloff, B., Schmukle, S. C., Nestler, S., \& Back, M. D. (2014). Accurate judgments of neuroticism at zero acquaintance: A question of relevance. Journal of Personality. DOI:10.1111/jopy.12097.

Jensen-Campbell, L. A., \& Malcolm, K. T. (2007). The importance of conscientiousness in adolescent interpersonal relationships. Personality and Social Psychology Bulletin, 33, 368-383.

Jensen-Campbell, L. A., Rosselli, M., Workman, K. A., Santisi, M., Rios, J. D., \& Bojan, D. (2002). Agreeableness, conscientiousness, and effortful control processes. Journal of Research in Personality, 36, 476-489.

John, O. P., \& Srivastava, S. (1999). The Big Five trait taxonomy: History, measurement, and theoretical perspectives. Handbook of Personality: Theory and Research, 2, 102-138.

Karney, B. R., \& Bradbury, T. N. (1995). The longitudinal course of marital quality and stability: A review of theory, methods, and research. Psychological Bulletin, 118, 3-34.

Karney, B. R., \& Bradbury, T. N. (1997). Neuroticism, marital interaction, and the trajectory of marital satisfaction. Journal of Personality and Social Psychology, 72, 1075-1092.

Kelly, E. L., \& Conley, J. J. (1987). Personality and compatibility: A prospective analysis of marital stability and marital satisfaction. Journal of Personality and Social Psychology, 52, 27-60.

Kenny, D. A., Kashy, D. A., \& Bolger, N. (1998). Data analysis in social psychology. In Gilbert, D., Fiske, S. T., \& Lindzey, G. (Eds.), Handbook of social psychology (4th ed., pp. 233-265) 1. New York: McGraw-Hill.

Kramer, A. D. (2010). An unobtrusive behavioral model of gross national happiness. In Proceedings of the SIGCHI Conference on Human Factors in Computing Systems (pp. 287-290). ACM.

Lansford, J. E., Yu, T., Pettit, G. S., Bates, J. E., \& Dodge, K. A. (2014). Pathways of peer relationships from childhood to young adulthood. Journal of Applied Developmental Psychology, 35, 111-117.

Lucas, R. E., Diener, E., Grob, A., Suh, E. M., \& Shao, L. (2000). Cross-cultural evidence for the fundamental features of extraversion. Journal of Personality and Social Psychology, 79, 452-468.

Lucas, R. E., \& Fujita, F. (2000). Factors influencing the relation between extraversion and pleasant affect. Journal of Personality and Social Psychology, 79, 1039-1056.

Lucas, R. E., Le, K., \& Dyrenforth, P. E. (2008). Explaining the extraversion/positive affect relation: Sociability cannot account for extraverts' greater happiness. Journal of Personality, 76, 385-414.

MacKinnon, D. P., Fritz, M. S., Williams, J., \& Lockwood, C. M. (2007). Distribution of the product confidence limits for the indirect effect: Program PRODCLIN. Behavior Research Methods, 39, 384-389.

Malouff, J. M., Thorsteinsson, E. B., Schutte, N. S., Bhullar, N., \& Rooke, S. E. (2010). The five-factor model of personality and relationship satisfaction of intimate partners: A meta-analysis. Journal of Research in Personality, 44, 124-127.

McAdams, D. P. (1995). What do we know when we know a person? Journal of Personality, 63, 365-396.

Mehl, M. R., \& Conner, T. S. (Eds) (2011). Handbook of research methods for studying daily life. London, England: Guilford Press.

Mehl, M. R., Gosling, S. D., \& Pennebaker, J. W. (2006). Personality in its natural habitat: Manifestations and implicit folk theories of personality in daily life. Journal of Personality and Social Psychology, 90, 862-877.
Mehl, M. R., Pennebaker, J. W., Crow, D. M., Dabbs, J., \& Price, J. H. (2001). The electronically activated recorder (EAR): A device for sampling naturalistic daily activities and conversations. Behavior Research Methods, Instruments, \& Computers, 33, 517-523.

Mehl, M. R., Vazire, S., Holleran, S. E., \& Clark, C. S. (2010). Eavesdropping on happiness: Well-being is related to having less small-talk and more substantive conversations. Psychological Science, 21, 539-541.

Mischel, W., \& Shoda, Y. (1995). A cognitive-affective system theory of personality: Reconceptualizing situations, dispositions, dynamics, and invariance in personality structure. Psychological Review, 102, 246-268.

Moore, K., \& McElroy, J. C. (2012). The influence of personality on Facebook usage, wall postings, and regret. Computers in Human Behavior, 28, 267-274.

Newcomb, A. F., Bukowski, W. M., \& Pattee, L. (1993). Children's peer relations: A meta-analytic review of popular, rejected, neglected, controversial, and average sociometric status. Psychological Bulletin, 113, 99-128.

Ong, E. Y., Ang, R. P., Ho, J., Lim, J. C., Goh, D. H., Lee, C. S., \& Chua, A. Y. (2011). Narcissism, extraversion and adolescents' self-presentation on Facebook. Personality and Individual Differences, 50, 180-185.

Ozer, D. J., \& Benet-Martinez, V. (2006). Personality and the prediction of consequential outcomes. Annual Review of Psychology, 57, 401-421.

Paunonen, S. V. (2003). Big Five factors of personality and replicated predictions of behavior. Journal of Personality and Social Psychology, 84, 411-424.

Preacher, K. J., \& Hayes, A. F. (2004). SPSS and SAS procedures for estimating indirect effects in simple mediation models. Behavior Research Methods, Instruments, \& Computers, 36, 717-731.

Preacher, K. J., \& Hayes, A. F. (2008). Asymptotic and resampling strategies for assessing and comparing indirect effects in multiple mediator models. Behavior Research Methods, 40, 879-891.

Roberts, B. W., Kuncel, N. R., Shiner, R., Caspi, A., \& Goldberg, L. R. (2007). The power of personality: The comparative validity of personality traits, socioeconomic status, and cognitive ability for predicting important life outcomes. Perspectives on Psychological Science, 2, 313-345.

Rosseel, Y. (2012). lavaan: An R package for structural equation modeling. Journal of Statistical Software, 48, 1-36.

Schaffhuser, K., Allemand, M., \& Martin, M. (2014). Personality traits and relationship satisfaction in intimate couples: Three perspectives on personality. European Journal of Personality, 28, 120-133.

Simmons, J. P., Nelson, L. D., \& Simonsohn, U. (2012). A 21 word solution. Retrieved from http://ssrn.com/abstract $=2160588$

Slatcher, R. B., \& Vazire, S. (2009). Effects of global and contextualized personality on relationship satisfaction. Journal of Research in Personality, 43, 624-633.

Solomon, B. C., \& Jackson, J. J. (2014). Why do personality traits predict divorce? Multiple pathways through satisfaction. Journal of Personality and Social Psychology, 106, 978-996.

Srivastava, S., Angelo, K. M., \& Vallereux, S. R. (2008). Extraversion and positive affect: A day reconstruction study of personenvironment transactions. Journal of Research in Personality, $42,1613-1618$.

Srivastava, S., Tamir, M., McGonigal, K. M., John, O. P., \& Gross, J. J. (2009). The social costs of emotional suppression: A prospective study of the transition to college. Journal of Personality and Social Psychology, 96, 883-897.

Stopfer, J. M., Egloff, B., Nestler, S., \& Back, M. D. (2013). Being popular in online social networks: How agentic, communal, and creativity traits relate to judgments of status and liking. Journal of Research in Personality, 47, 592-598.

Tamir, D. I., \& Mitchell, J. P. (2012). Disclosing information about the self is intrinsically rewarding. Proceedings of the National Academy of Sciences, 109, 8038-8043. 
Vater, A., \& Schroder-Abe, M. (2015). Explaining the link between personality and relationship satisfaction: Emotion regulation and interpersonal behavior in conflict discussion. European Journal of Personality, 'THIS ISSUE; INSERT CORRECT PAGE NUMBERS WHEN DETERMINED'.

Vazire, S. (2006). Informant reports: A cheap, fast, and easy method for personality assessment. Journal of Research in Personality, 40, 472-481.

Vazire, S. (2010). Who knows what about a person? The self-other knowledge asymmetry (SOKA) model. Journal of Personality and Social Psychology, 98, 281-300.

Vazire, S., Wilson, R. E., Solomon, B., Bollich, K., Harris, K., Weston, S.,...Jackson, J. J. (2015). Personality and interpersonal roles (PAIRS). Study in progress.

Q7 Wagner, J., Lüdtke, O., Roberts, B. W., \& Trautwein, U. (2014). Who belongs to me? Social relationship and personality characteristics in the transition to young adulthood. European Journal of Personality, 28, 586-603.
Watson, D., \& Slack, A. K. (1993). General factors of affective temperament and their relation to job satisfaction over time. Organizational Behavior and Human Decision Processes, 54, 181-202.

Wilkinson, R. B., \& Walford, W. A. (2001). Attachment and personality in the psychological health of adolescents. Personality and Individual Differences, 31, 473-484.

Wood, D. (2007). Using the PRISM to compare the explanatory value of general and role-contextualized trait ratings. Journal of Personality, 75, 1103-1126.

Wood, D., \& Roberts, B. W. (2006). Cross-sectional and longitudinal tests of the personality and role identity structural model (PRISM). Journal of Personality, 74, 779-810.

Zalk, M. H. W., Zalk, N. V., Kerr, M., \& Stattin, H. (2014). Influences between online-exclusive, conjoint and offline-exclusive friendship networks: The moderating role of shyness. European Journal of Personality, 28, 134-146.

\section{APPENDIX A: ECOLOGICAL MOMENTARY ASSESSMENT (EMA)}

'Please take a moment and think of what you were doing from 11 AM-noon (2-3 PM, 5-6 PM, 8-9 PM).'

I was asleep the entire hour (Yes/No)

Were you...(Completely alone/ Around others)

Were you interacting with other people? $(0,1,2,3-5,3+5)$ The following items were answered on a 1-5 Likert-type scale:

Motivated to do well academically

Authentic

Outgoing, sociable

Quiet

Self-esteem (low to high)

Lazy

Reliable

Happy

Worried

Relaxed

Depressed, blue

Lonely

Close, connected

Keep your emotions to yourself

Positive emotion (not at all to a lot)

Negative emotion

Willpower/self-control

Feel like being around others

Considerate, kind

Rude

In a few words, what were you doing from 8 PM-9 PM? (Open Response)

In this situation, were you free to behave however you wanted?

How stressful was the situation?

How common/familiar was the situation?

How much did you want to be there?
From 8 PM-9PM, check the items that occurred:

Stayed mostly in your room/house

Studied/worked

Listened to music

Felt tired

In pain/sick

Did something for someone else

Passively looked at Facebook

Actively did something on Facebook

Talked on the phone/Skype

Watched a video/tv/movie

Went to class

Interacted with family

Interacted with romantic partner

Interacted with local best friend

Interacted with another close friend

Something good happened

Something bad happened

What was the good/bad thing that happened?

Good (Open Response)

Bad (Open Response)

Please refer to the people you interacted with for the following questions:

How well do you know them?

How much do you like them?

Compared to them, how much power/social status do you have?

How much did you care about how you came across to them? How superficial (i.e. shallow) to substantive (i.e. deep) were the conversations?

How much did you self-disclose? 


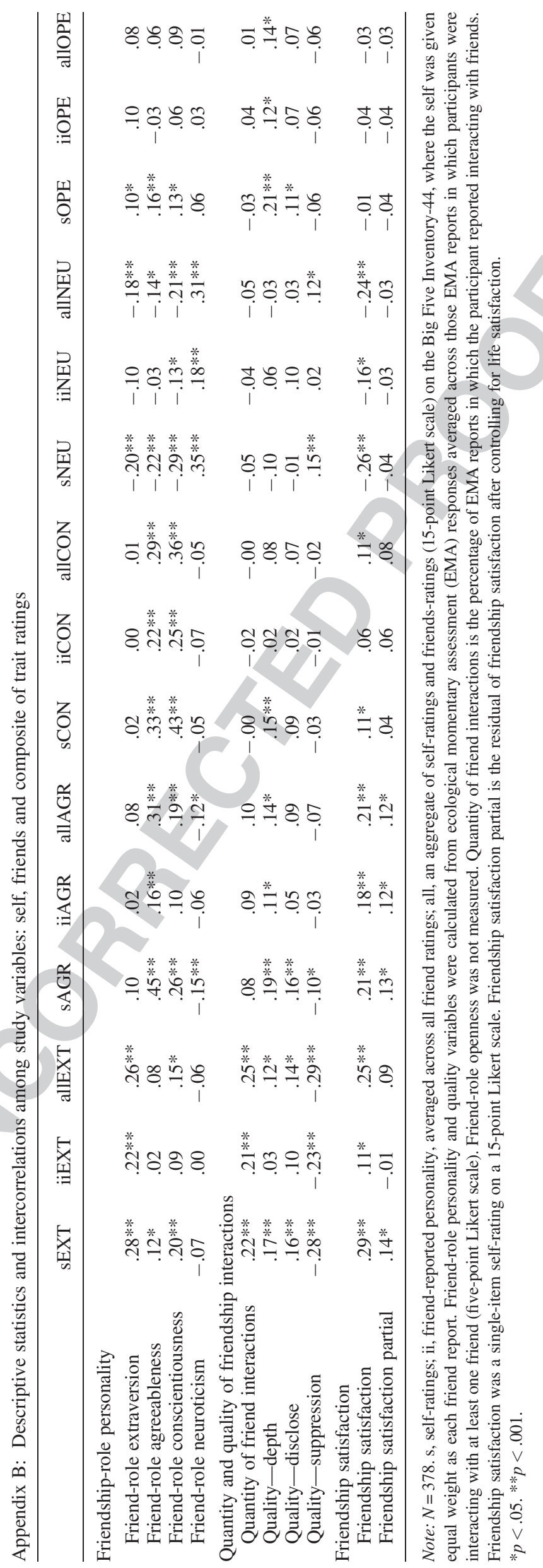




\section{Author Query Form}

\section{Journal: European Journal of Personality}

\section{Article: per_1996}

Dear Author,

During the copyediting of your paper, the following queries arose. Please respond to these by annotating your proofs with the necessary changes/additions.

- If you intend to annotate your proof electronically, please refer to the E-annotation guidelines.

- If you intend to annotate your proof by means of hard-copy mark-up, please use the standard proofing marks. If manually writing corrections on your proof and returning it by fax, do not write too close to the edge of the paper. Please remember that illegible mark-ups may delay publication.

Whether you opt for hard-copy or electronic annotation of your proofs, we recommend that you provide additional clarification of answers to queries by entering your answers on the query sheet, in addition to the text mark-up.

\begin{tabular}{|c|l|c|}
\hline Query No. & \multicolumn{1}{|c|}{ Query } & Remark \\
\hline Q1 & $\begin{array}{l}\text { AUTHOR: Please confirm that given names (red) and surnames/family names (green) } \\
\text { have been identified correctly. }\end{array}$ & YES \\
\hline Q2 & AUTHOR: Please check authors and their affiliations if correct. & YES \\
\hline Q3 & AUTHOR: Please check keywords if presented correctly. & YES \\
\hline Q4 & AUTHOR: The expansion of 'PRISM' has been modified. Please check if appropriate. \\
\hline Q5 & AUTHOR: Please provide volume number for reference Greene, 2006. & YES \\
\hline Q6 & AUTHOR: Please provide page ranges for reference Gross, 1998. & \begin{tabular}{|l|} 
AUTHOR: Reference “Wagner et al. (2014)" is not cited in the text. Please indicate \\
Q7
\end{tabular} \\
\hline
\end{tabular}


Required software to e-Annotate PDFs: Adobe Acrobat Professional or Adobe Reader (version 7.0 or above). (Note that this document uses screenshots from Adobe Reader $\mathrm{X}$ )

The latest version of Acrobat Reader can be downloaded for free at: http://get.adobe.com/uk/reader/

Once you have Acrobat Reader open on your computer, click on the Comment tab at the right of the toolbar:

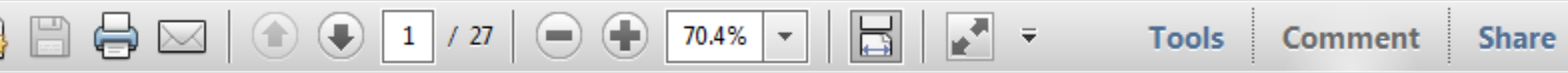

This will open up a panel down the right side of the document. The majority of tools you will use for annotating your proof will be in the Annotations section, pictured opposite. We've picked out some of these tools below:

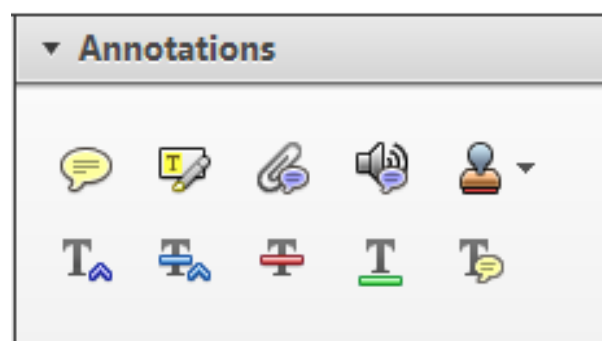

1. Replace (Ins) Tool - for replacing text.

Strikes a line through text and opens up a text box where replacement text can be entered.

How to use it

- Highlight a word or sentence.

- Click on the Replace (Ins) icon in the Annotations section.

- Type the replacement text into the blue box that appears.

Idard tramework for the analysis of $\mathrm{m}$ icy-Nevertheless, it also led to exog،

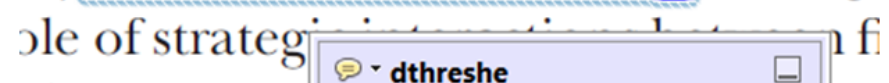
aber of comp 08/06/2011 15:58:17 is that the s1 nain compo: be level, are exc nc

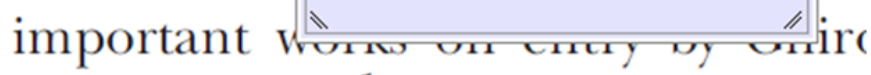
M heneferth) ${ }^{1}$ we anen the "hlarl $\mathrm{l}$

3. Add note to text Tool - for highlighting a section to be changed to bold or italic.

T Highlights text in yellow and opens up a text box where comments can be entered.

\section{How to use it}

- Highlight the relevant section of text.

- Click on the Add note to text icon in the Annotations section.

- Type instruction on what should be changed regarding the text into the yellow box that appears.

namic responses of mark ups ent with the VAR evidence

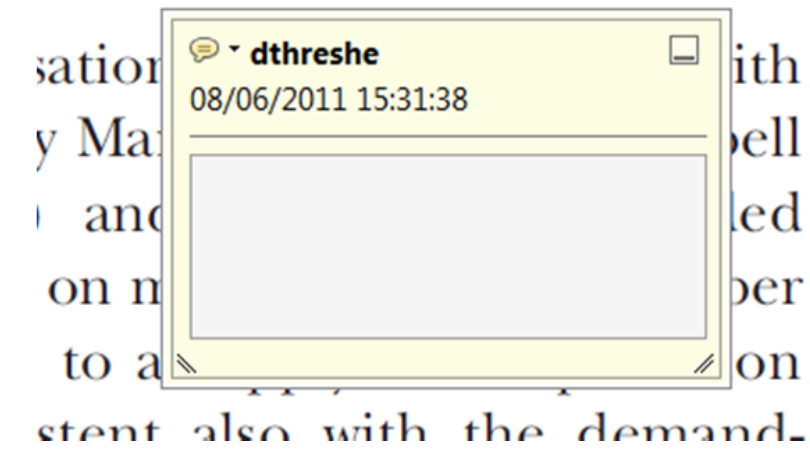

2. Strikethrough (Del) Tool - for deleting text.

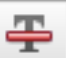

Strikes a red line through text that is to be deleted.

How to use it

- Highlight a word or sentence.

- Click on the Strikethrough (Del) icon in the Annotations section.

there is no room tor extra prohts al c ups are zero and the number of ret) values are not determined by Blanchard and Kiyotaki (1987), sfect competition in general equilil ts of aggregate demand and supply lassical framework assuming monol eph on evorenous number of firme

4. Add sticky note Tool - for making notes at specific points in the text.

Marks a point in the proof where a comment needs to be highlighted.

How to use it

- Click on the Add sticky note icon in the Annotations section.

- Click at the point in the proof where the comment should be inserted.

- Type the comment into the yellow box that appears.

iaisu airu suppiy sirucks. hivsl ui

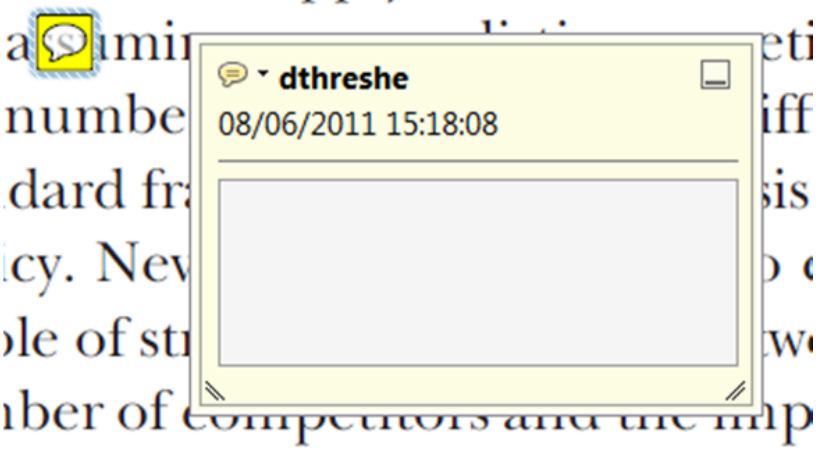

is that the structure of the secto. 
5. Attach File Tool - for inserting large amounts of text or replacement figures.

Inserts an icon linking to the attached file in the appropriate pace in the text.

How to use it

- Click on the Attach File icon in the Annotations section.

- Click on the proof to where you'd like the attached file to be linked.

- Select the file to be attached from your computer or network.

- Select the colour and type of icon that will appear in the proof. Click OK.

E N D

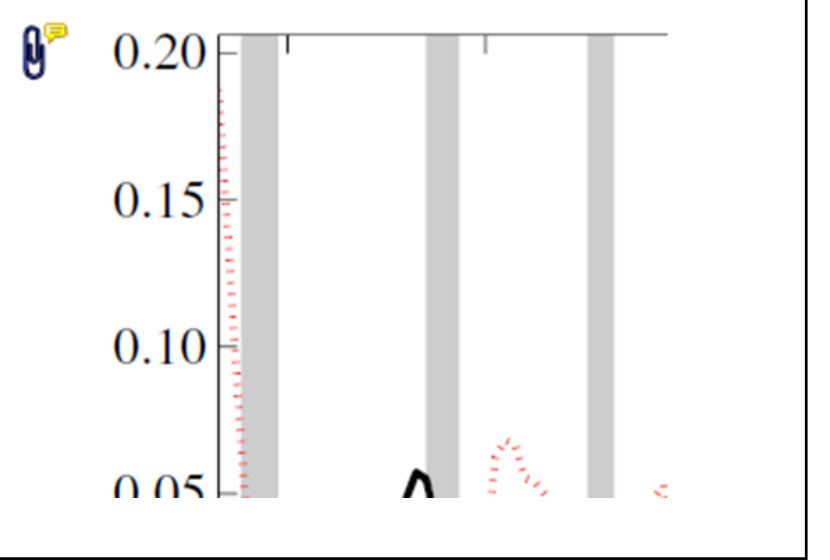

6. Add stamp Tool - for approving a proof if no corrections are required.

- Inserts a selected stamp onto an appropriate place in the proof.

\section{How to use it}

- Click on the Add stamp icon in the Annotations section.

- $\quad$ Select the stamp you want to use. (The Approved stamp is usually available directly in the menu that appears).

- Click on the proof where you'd like the stamp to appear. (Where a proof is to be approved as it is, this would normally be on the first page).

or the business cycie, starting with the on perfect competition, constant ret

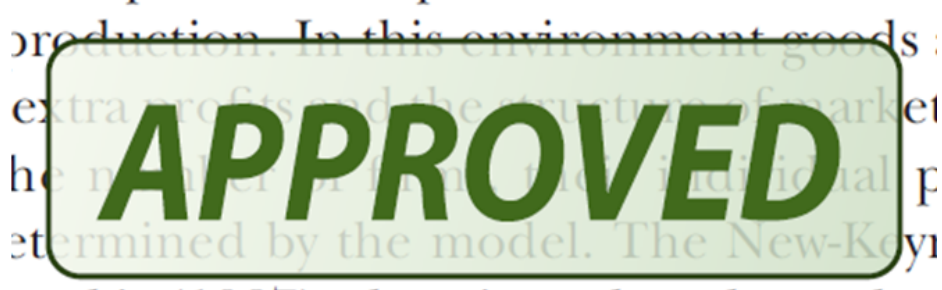
otaki (1987), has introduced produc general equilibrium models with nomin:

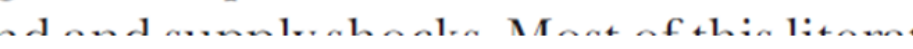

- Drawing Markups

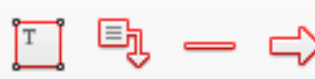

$0 \bigcirc \sqrt{6} \otimes$

\section{How to use it}

- Click on one of the shapes in the Drawing Markups section.

- Click on the proof at the relevant point and draw the selected shape with the cursor.

- To add a comment to the drawn shape, move the cursor over the shape until an arrowhead appears.

- Double click on the shape and type any text in the red box that appears.
7. Drawing Markups Tools - for drawing shapes, lines and freeform annotations on proofs and commenting on these marks.

Allows shapes, lines and freeform annotations to be drawn on proofs and for comment to be made on these marks.

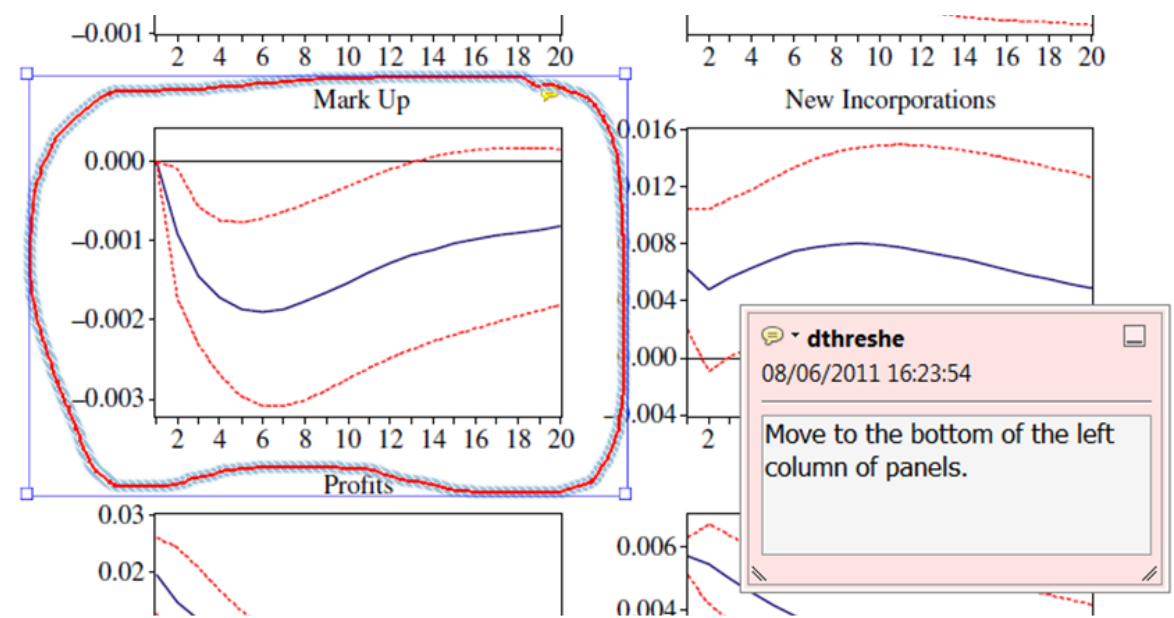

For further information on how to annotate proofs, click on the Help menu to reveal a list of further options:

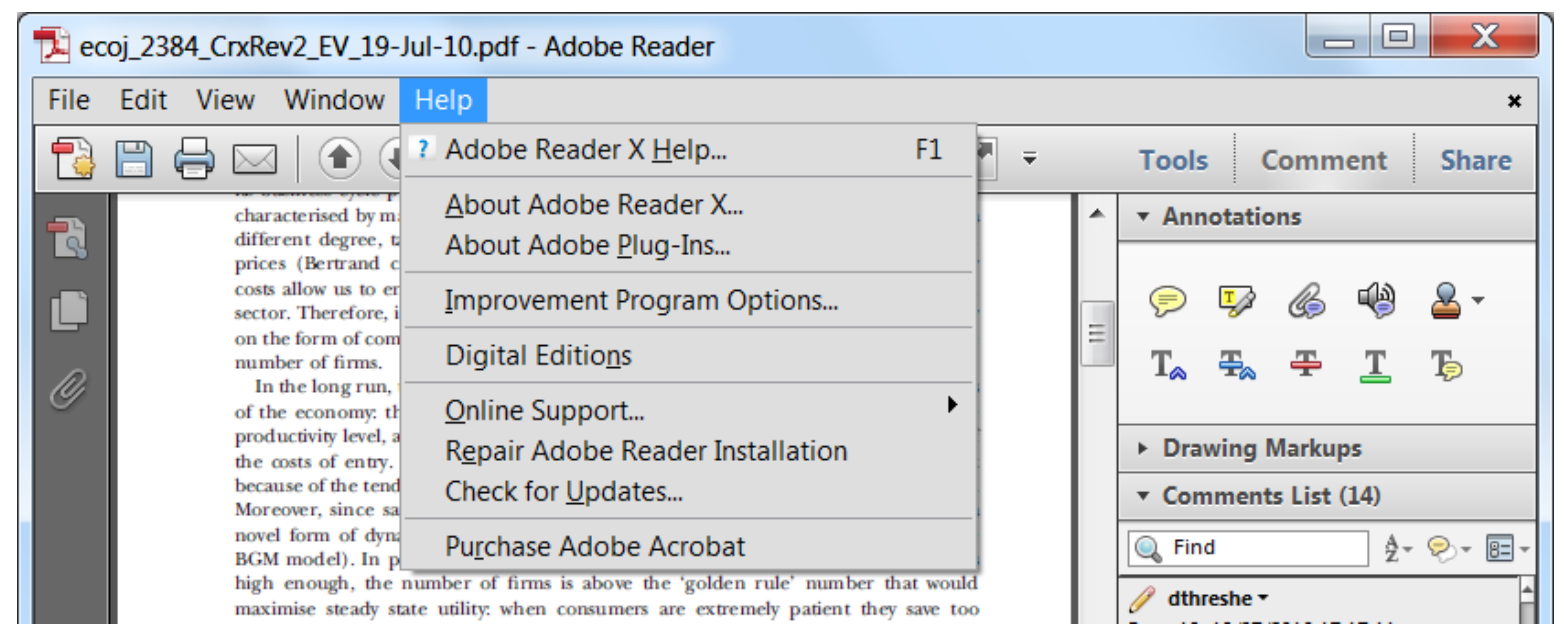

